\title{
A Beacon of Light: Applying Choice Theory to the COVID-19 Pandemic
}

\author{
Kristin A. Vincenzes", Ian MacGregor, and MacKenzie Monaghan \\ Department of Social Work and Counseling, Lock Haven University. United States.
}

Article Details
Article Type: Research Article
Received date: $02^{\text {nd }}$ September, 2021
Accepted date: $20^{\text {th }}$ November, 2021
Published date: $23^{\text {th }}$ November, 2021

"Corresponding Author: Kristin A. Vincenzes, Ph.D., LPC, NCC, ACS, BC-TMH, Associate Professor, Department of Social Work and Counseling, Lock Haven University. United States. E-mail: KAV813@lockhaven.edu

Citation: Vincenzes, K.A., MacGregor, I., \& Monaghan, M., (2021). A Beacon of Light: Applying Choice Theory to the COVID-19 Pandemic. J Ment Health Soc Behav 3(2):151. https://doi.org/10.33790/jmhsb1100151

Copyright: $\mathbb{C} 2021$, This is an open-access article distributed under the terms of the Creative Commons Attribution License $\underline{4.0}$, which permits unrestricted use, distribution, and reproduction in any medium, provided the original author and source are credited.

\begin{abstract}
This paper provides an application of William Glasser's (1998) choice theory and Randy Pausch's (2007) "lessons learned" to the current worldwide health pandemic, COVID-19. Reflective questions are included to support mental health workers as they engage with people impacted by COVID-19. Implications for consumers, providers, and policymakers are provided.
\end{abstract}

Keywords: Choice Theory, Basic Needs, COVID-19, Last Lecture

\section{Introduction}

As COVID-19 continues to barrel across the world, it leaves citizens and societies juggling a myriad of challenges. Nations closed and enforced "stay at home" orders. Parents lost jobs yet still try to provide for their families. Companies transformed from brick-andmortar to the cyber world. Small businesses either closed or are struggling to maintain some type of product to pay the bills. Stock markets crashed and came back again. These are just some of the consequences of the COVID-19 battle. While we initially saw hope when the number of COVID-19 cases began to decrease, new variants of the virus now continue to threaten the sustainability of societies.

As the world reflects on the impacts of the pandemic, people are still figuring out how to create a "new normal." Nothing is the same nor will it be the same. As the world watches and wonders what the long-term impacts will be, William Glasser's [1] choice theory and Randy Pausch's The Last Lecture can provide guiding beacons of light. While Glasser's choice theory was initially introduced over three decades ago and Pausch's lecture was broadcasted over a decade ago, the interconnection of theory and "lessons learned" are even more radiant during this worldwide crisis. Glasser's [1] choice theory claims that people have five basic needs: fun, power, freedom, survival, and love and belonging. Choice theory provides the foundation to support people's desires to gain control over their lives. This theory intertwined with Randy Pausch's "lessons learned" can guide individuals on their journey to re-gaining that control during these challenging times. As Pausch stated in his last lecture, "We cannot change the cards we are dealt, just how we play the hand" [2]. This paper provides an application of choice theory and "lessons learned" to the current worldwide health crisis while also providing reflective questions to support mental health workers as they engage with people impacted by COVID-19.

\section{COVID-19}

SARS-CoV-2, otherwise referred to as COVID-19 or 2019 novel coronavirus, is a severe acute respiratory syndrome caused by mutations throughout the coronavirus genome [3]. The World
Health Organization [4] released the official viral name as "severe acute respiratory syndrome coronavirus 2 " and the disease it causes as "coronavirus disease." This strain originated out of Wuhan, Hubei Province in China during the latter months of 2019 from an animal reservoir [5]. This identifies the emergence of the COVID-19 etiologically as animal to person transmittance. Those who contracted COVID-19 despite having no exposure to an infected animal source indicated person-to-person spread, which became the primary form of the disease's transmittance [5].

COVID-19 was first reported December 31, 2019 to the World Health Organization Country Office in China as a cluster of pneumonia cases with unknown etiology [5]. On January 12, 2020, China publically released the genetic sequencing of the virus for further research and on January 30, 2020 a Public Health Emergency of International Concern was issued by the WHO Director General with advisory from the Emergency Committee. On February 11, 2020, the World Health Organization announced the name as COVID-19 and one month later on March 11, 2020 it was declared a pandemic [5]. Even though vaccines were developed and 5,356,685,590 doses, as of September 2, 2021, have been administered, the threat to the world is still at large. The looming question is: How can people cope with a pandemic that has lasted for almost two years with no end in sight?

\section{Choice Theory}

William Glasser [1] initially coined choice theory to help understand why people act and think the way they do. Glasser [1] believed that people are intrinsically motivated to meet five innate basic needs: fun, power, survival, freedom, and love and belonging. These needs are universal and often overlap with each other. In the event that a person is not able to meet one of those basic needs, it creates pain and discomfort. As an individual makes choices to balance pain and pleasure, it impacts the person's total behavior: acting, thinking, feeling, and physiology [1]. Glasser [1] believed that a person can directly control their thoughts (mind) and behavior (action) whilst indirectly controlling their feelings and how their body responds.

\section{The Last Lecture}

Similar to Glasser, Randy Pausch shared an optimistic perspective on living life. Pausch was a professor of computer science at Carnegie Mellon University in Pittsburgh, Pennsylvania. After being told that he had three to six months to live due to pancreatic cancer, Randy Pausch gave his last lecture in an auditorium at Carnegie Mellon [6]. During this lecture on September 18, 2007, he shared with students, colleagues, and friends the lessons he learned during his life. Soon after this lecture, he wrote the book, The Last Lecture, to further 
capitalize and share these life lessons. Glasser and Pausch both focused on the present moment and how people have the choice to think and act differently even in the midst of adversity.

\section{Choice Theory and "Lessons Learned" as a Catalyst}

Glasser [1] believed people are successful if they take responsibility for their choices. While external events may impact a person's thoughts and behaviors, an individual ultimately has the choice on how they want to think and act. The COVID-19 pandemic impacted the entire world with no rock left unturned. That being said, every person and nation has the choice on how to respond to this crisis. As Pausch reflected on his terminal diagnosis and how he wanted to spend his remaining days, he asked himself the question, “...Am I a fun-loving Tigger or am I a sad-sack Eeyore" [2](p. 180). Even as Pausch knew he was dying, he had the choice to be sad, upset, and angry about the situation or to be happy and enjoy the time he had left.

While terminal cancer is different than a global pandemic, both situations are not desirable nor wanted. Furthermore, both situations have the opportunity to negatively impact people's daily lives even to the point of death. With COVID-19, nations were told to stay at home and avoid contact with others, manage job transformation or loss, and abruptly redefine the means by which needs are met. For those working from home, personal and professional boundaries were blurred. Those who lost their jobs were anxious and afraid of how they will pay the bills. Those who kept their jobs now are plagued by the choice of whether or not to get the vaccine. With that choice comes consequences such as job sustainability or job loss, depending on the individual's choice. While each experience is unique and has different challenges, people had and still, to this day, have the choice in how they respond to their situation. Do people choose to look at only the negative impacts or do people take solitude in the present moment and try to have an optimistic perspective?Glasser [1] believed that the choices people make are connected to one's effort to innately meet their basic needs.

\section{Fun}

One of the five basic needs is the need for fun. Glasser [1] maintained that learning is necessary for survival and because fun is the genetic reward for learning, a need for fun is built directly into a human's genetic code. The concept for fun seems to be timelessly and universally accepted, desired, and enjoyed. Current Western culture associates fun with terms like play, humor, relaxation, and pleasure [1]. According to Glasser [1], fun is the easiest need to satisfy, is associated with copious amounts of laughter, and is best-served socially. Some of the greatest minds in history who have contributed to society, including Pausch [2], encourage us to, above all else, never stop having fun. If a person's ability to have fun in social settings is taken away, they can be stripped of a defining characteristic in what it means to be human.

Since COVID-19, people had the opportunity to engage in more fun and relaxing activities. In the Western culture where fast-paced routines and structure dictate every moment in a day, the abrupt change to less structure and more time for pleasurable activities was like a jolt to the system. Unfortunately in Western societies, the focus is more on one's job and less on having fun. One of Pausch's lessons he shared was to, "never lose the childlike wonder," thus he reiterated the importance of having fun [6]. Childlike wonder could also be connected to the innate ability to be creative and imaginative. These skills were demonstrated during the pandemic when family and friends connected via platforms such as FaceTime and Zoom for virtual get-togethers, happy hours, and playing games. While nothing can replace the essence of being physically together and having fun, creativity allowed people to enjoy each other in innovative ways.

\section{Thoughts/Questions for Reflection}

1. Meet the client where they are. Forcing them to do anything may result in them losing their creativity and will [7].

J Ment Health Soc Behav

Volume 3. 2021. 151
2. "What does having fun mean to you?"

3. "What can you do during stressful times that might be fun or relaxing?"

4. "What benefits do you see from doing something fun?"

5. "What have you done in the past that was pleasurable?"

6. "What cognitive, emotional, psychological, spiritual, and physical changes do you notice before and after doing something fun?"

\section{Power}

Another basic need that Glasser [1] believed was essential to human motivation was power. According to Glasser [1], power is an insatiable need that is unique to humans. A person's need to feel poweful will likely be judged with criticism, but the desire to make a difference, achieve great things, and be respected are concepts that are relatable for most people. In Pausch's (2007) Last Lecture speech, only months before his projected death, he spoke at length about one of the major tenets of power; the importance of leaving a legacy. In Western cultures, people often meet this need of power through their work. Whether people are managing others, training a new employee, using skills to fix someone's car, closing a big deal, or deciding who passes and fails a class, the desire to matter and be recognized are often quenched in a person's work. One's self-image and self-esteem, which can be directly related to their mental health, are tied to their ability to achieve their need for power. Glasser [1] explained that if people do not satisfy the need for power, then they are likely experiencing the pain of being powerless. Empowered with this knowledge, it is easy to see how a nation of suddenly jobless, and thus powerless, individuals can feel overwhelmed by the mystery of their newfound feelings of depression and anxiety.

While COVID-19 continues to transform societies, the "old normal" morphs into the "new normal," thus potentially causing tension between people. Individuals may become frustrated and irritable that lifestyles are rapidly evolving and they may have no control over it. It may be easier for people to throw their hands up and say, "it's impossible," "how in the world can this be done?" or "I might as well give in and get the vaccine; otherwise I'll be fired." People who were once extremely competent in their ability to do their jobs "face-to-face" may feel incompetent to do it virtually. People who lost their jobs due to furloughs, retrenchment, or the business going bankrupt may think that they've lost their identity or that they no longer matter. It is in these times when people want to "Be prepared [because] 'luck' is where preparation meets opportunity" [6]. When jobs or plans are altered, it is important to be prepared for the new opportunities that may happen. Too often, if people negatively focus on change, the new opportunities are missed. Openness can lead to a new fulfillment of power and success.

\section{Thoughts/Questions for Reflection}

1. "How are you making a difference right now?"

2. "How important is it for you to be recognized for your contributions and support?"

3. "How does your situation now impact your ability to feel competent in your work?"

4. "How might this experience help you in the future?"

5. "What have you learned about yourself and your ability to adapt to change?"

6. "What new skills do you have that will help you moving forward in your job?"

7. "Were there activities, quotes, or general coping practices that helped you adjust to your newly defined responsibilities? If not, looking back, what would you encourage yourself to do?" 


\section{Survival}

According to Glasser [1], survival is the most basic of all needs and is programmed into every living organism ever created. Whether an organisim is aware of this fact or not, the desire for survival of self, family, and species is at the core of every thought, behavior, and choice. Glasser [1] maintained that as humans became aware of this need for survival, they gradually changed their behaviors and survival rates improved. It is from the human's greatly improved ability to surivive that the needs for love, power, freedom, and fun evolved [1]. Glasser's [1] view on survival is in alignment with Maslow's perspective that humans require food, water, shelter, health, safety, and security. In many cultures, these needs are driven by an individual's monetary resources. Unfortunately, during the current pandemic, people lost their jobs, which resulted in unemployment rates ranging from $5.2 \%$ in Nebraska to $25.3 \%$ in Nevada [8]. This outcome of the global health pandemic threatens to destroy people's ability to meet their basic needs.

Survival of a person and species requires adaptability and flexibility, or "survival of the fittest" as Charles Darwin stated. COVID-19 forced people to alter their daily lifestyles in an effort to meet their most basic needs. One of the ways society adapted was in the use of technology as the primary source of continuing employment. For jobs that could use technology to accomplish their responsibilities, employees could continue working. Jobs that could not be translated to a virtual world unfortunately required them to shut down or close. This meant a loss of income for many people, which in turn impacted one's financial resources to afford shelter, food, water, and healthcare. As with any challenge, "brick walls are there for a reason"[2] (p. 79). Sometimes the walls may seem extraordinarily high and we may want to give up but we "[can't] bail [because] the best gold is at the bottom of barrels of crap" [6]. Sometimes people don't know the purpose or reason for the struggle or challenge, but hopefully in time they can look back and see a purpose for it all. Perserverance, determination, adaptability, and flexibility all support the ability to survive.

\section{Thoughts/Questions for Reflection}

1. "How are/were your needs being met on a daily basis?"

2. "What changes happened to help you meet those needs? How could those changes help you in the future?"

3. "What do you need in order to feel safe and secure now?"

4. "What does it mean to be a survivor? How were you a survivor during that time?"

5. "What personal characteristics, skills, or attributes contributed to your ability to meet your basic needs?"

6. "How did you respond to the 'brick walls' in front of you?"

7. "What lessons did you learn throughout and after the trials, discomfort, and obstacles?"

\section{Freedom}

A defining characteristic of what it means to be an American is the constitutional right to be free. According to Glasser [1], the human need for freedom is satisfied by having choices, moving freely and autonomously without restriction, and feeling pride in proclaiming one's independence. As Americans, the concept of freedom comes easily and only warrants concern when people perceive this freedom as being threatened [1]. For individuals who never paid attention to the inherent beauty in freedom, the sudden loss of these freedoms is certain to be noticed. To Glasser [1], the enemy of freedom is external control. A global health crisis which forces governments to control every aspect of life, from where its citizens can eat, shop, walk, work, play, and exist will certainly cause friction as our defining human need to live freely is repressed. As the pandemic continues, now the freedom to choose whether or not to get the vaccine controls whether a person is permitted to remain employed at an organization. Discrimination and segration are occurring across the nation because people want the freedom to make their own choices about the vaccine.

While people may wince at these restrictions, Pausch provided perspective to these life-altering changes. He stated that while people may have rights, they must also understand responsibilities [2] (p. 175). One of these responsibilities is to contribute to the common good. When reviewing the global impacts of the pandemic, as of Septmeber 2, 2021, there were 218,666,689 total confirmed cases and 4,546,775 confirmed deaths due to COVID-19 [9]. While no death is acceptable, these numbers could have been higher if it was not for significant societal efforts to physically distance themselves from others. Furthermore, when looked at broadly, this pandemic may provide societal freedom for the United States. For example, the U.S. notoriously relied on China for many materials and products. Perhaps this pandemic may support the need for the United States to rely more on its own nation to make its products, thus creating autonomy from other countries. While citizens may have lost the freedom to walk around or go to stores for a period of time, society as a whole may gain ultimate freedom from other countries. This freedom could even result in more jobs for U.S. citizens, which in turn could significantly decrease unemployments rates in the long run.

\section{Thoughts/Questions for Reflection}

1. "What is it that you want but cannot have?" (Bin Jusoh, 2019)

2. "What can you do to help yourself get what you want?"

3. "What does 'freedom' look like to you?"

4. 'When your definition of 'freedom' is challenged, how do you respond?"

5. "Is personal discomfort acceptable when others assert that it is for the 'common good'?"

6. "What do you need to feel free? Can that be attained without political reform?"

\section{Love and Belonging}

According to Glasser [1], the need for love and belonging come to us in the form of human connection. Love will look and feel differently depending on who the bond is shared with, but healthy involvement with friends, family members, intimate partners, colleagues, organizations, and even pets will satisfy the innate human need to feel love and belonging. To Glasser [1], experiencing love is pure ecstasy, but the absence of love is the greatest of all human miseries. For many people around the world who are not presently in intimate relationships, dating apps and social networking sites provided this necessary human connection. For example, the toprated dating and human connection app Tinder was said to have 57 million users worldwide [10]. Essentially 57 million people from a single app were likely socially isolating themselves but still looking for the warmth of human connection.

As the world transformed into cyberspace, people were not allowing "physical distancing" to determine their "social distancing." If the United States looks into their past, notoriously unfortunate life altering situations propelled the nation to come together. During COVID-19, nations came together to help others, which Glasser [1] believed was a way that people could care for one another or offer humanitarian aid. Stories were broadcasted on Facebook, Instagram, and across TV screens sharing their support for each other. Adults and kids were making masks for others and donating them while others lived for over a month at a factory to make gear for healthcare workers [11]. Companies donated funds to support local small businesses while others shared random acts of kindness to support those around them. People supported each other as societies 
learned to flourish by working together instead of against each other. "When we're connected to others, we become better people"[2] (p. 176).

\section{Thoughts/Questions for Reflection}

1. "What do you want from others during this time?"

2. "How do you want to support yourself, others, society during this time?"

3. "When you get what you want, how do you feel (emotionally, physically, spiritually)?"

4. "How do you feel loved and cared for by others?"

5. "What do the terms 'love' and 'belonging' mean to you?"

6. "How do others show you that you are loved and belong?"

7. "How do you show others that you love them and they belong?"

\section{Implications}

As we look at COVID-related challenges facing the world, there are implications that could be useful for various stakeholders. Key stakeholders in the fight against COVID include the general public (consumers), those offering mental and physical health services (providers), and legislators at local, state, and federal levels (policymakers). The implications for these three identified groups don't exist in separate vaccums but instead, overlap, interact, and all contribute to a shared outcome. Stakeholders across all three sectors can contribute in unique efforts to create positive social change for society. Everyone can share in supporting Glasser's concepts of fun, power, survivial, freedom, and love and belonging. With everyone working together, we can bridge the gap from "what used to be" to "what is now."

\section{Consumers}

This group of stakeholders includes the population-at-large who continue to require mental health services to fulfill ongoing needs. Consumers have more power over their lives than what they may initially think. People as consumers can choose to cut back on superfluous spending and unecceasry items, can choose to waste less and save more, and rewrite the chronicle that is their lifestyle. Consumers may not be able to control what the government mandates or the impact of the virus; however, they have the power to control how they respond. Consumers can choose to adapt by reflecting and creating new narratives. They can sustain relationships and human connection by choosing to be proactive instead of reclusive. Rather than continuing to be disappointed, angry, and bitter about what has transpired since March 2020, consumers have the control to reframe the situation and move beyond it. This feedom to choose is something no one can take away from them.

\section{Providers}

Stakeholders within this classification include individuals offering mental and physical health services such as professional counselors, social workers, psychiatrists, psychologists, nurses, and physicians. As COVID-19 continues and society learns how to effectively manage it, nations will need to adapt to a new normal. This new normal may significantly impact people's everyday lives and their mental health. For example, people may experience fear, anxiety, and stress about going back into public or whether or not to get the vaccine. Doctor's offices may see an increase in appointments or requests for COVID-19 testing as people decipher the differences between the common cold, allergies, and COVID-19. They may simultaneously see individuals with co-occurring issues of both physical and mental health needs. Mental health workers may see a rise in alcohol and substance use disorders because it was either a coping mechanism or the shut down impacted people's ability to access the resources needed to get help. People may experience grief and loss issues related to the death of a loved one or perhaps loss of employment, identities, and their old "normalcy." Parents may struggle with childcare or planning for the future in a time of unscertainty with PreK-12 schools deciding whether to reopen, with or without masks, or to stay virtual. All of these concerns lead the importance of integrated behavioral health systems required to address the multifaceted needs of citizens.

In addition to a systemic approach of meeting consumers' needs, mental health professionals, specifically, may need to help clients process their lived experiences. As Pausch stated, "Experience is what you get when you don't get what you wanted" [2] (p. 149). No one wanted this to happen, but it did. Now society must process it and learn from it. Many people are fearful of the resurgence of the Coronavirus and its variants during the upcoming year and how that may once again impact their daily lives. This is an opportunity for providers to provide both intervention and prevention. Whether COVID-19 returns at the projected rates or not, providers will need to adapt to the current societal needs so that consumers can survive their "new normal."

\section{Policymakers}

This group of stakeholders include those who propose, debate, and pass legislation that impacts local and global communities. Policymakers could join the forces to create societal change. With legislative power comes great responsibility; these individuals could use their "power" to encourage adaptability of the profession's mode of services. This will promote consumers' abilities to have the freedom to choose their provider, thus encouraging connection with a therapist regardless of physical location.

Since many citizens are still fearful about COVID-19 and the potential of contracting the virus, we need to continue to adapt the way of providing services. Policymakers can continue to support the use of telemental health services and ensure that this method of service is reimbursed by insurance companies. In addition, policymakers can advocate for the approval of tele-supervision hours for industryprofessionals who are applying for their state license as a clinician. This flexibility will increase the opportunity for more providers to be licensed, which will support the survival of our profession and the increased need for mental health services.

Another opportunity for policymakers to become social change agents is to join the interstate counseling compact. This will promote telemental health services as well as encourage consumers to have the power and freedom to access services that perhaps are not within their local communities. Furthermore, consumers will be able to access more specialists who may reside across state lines. By promoting this access, policymakers will support citizens' continued need for human connection and mental health services.

\section{Conclusion}

Pausch's "lessons learned" focused on the inter- and intrapersonal ways of living. A person's choice on how to respond to potentially negative situations are connected to their innate needs of fun, power, survival, love and belonging, and ultimately freedom: freedom of choice and control over how people will think and act. Unfortunately, COVID-19 is here to stay but people have the choice in how they respond to the new normal. Choice theory can help providers identify clients' unmet needs and then develop alternative ways of thinking and acting. The new perspectives will further impact the way people feel, both physiologically and emotionally.

Conflict of interest: The authors declare no conflict of interest.

\section{Reference}

1. Glasser, W. (1998). Choice theory: A new psychology of personal freedom. Harper Collins.

2. Pausch, R. (2008). The last lecture. Hachette Books. 
3. Phan, T. (2020). Genetic diversity and evolution of SARSCoV-2. Infection, Genetics and Evolution, 81, 104260. doi: 10.1016/j.meegid.2020.104260

4. World Health Organization. (2020a). Naming the coronavirus disease (COVID-19) and the virus that causes it. Retrieved June 25, 2020, from https://www.who.int/emergencies/diseases/ novel-coronavirus $2019 /$ technicalguidance/naming-thecoronavirus-disease-(covid-2019)-and-the-virus-that causes-it

5. World Health Organization. (2020b, April 27). WHO Timeline - COVID-19. Retrieved June 25, 2020, from https://www.who. int/news-room/detail/27-04-2020-who-timeline---covid-19

6. Carnegie Mellon University. (2007, December 20). Randy Pausch last lecture: Achieving your childhood dreams [Video]. YouTube. https://www.youtube.com/watch?v=ji5_MqicxSo

7. Bin Jusoh, A. J. (2019). Choice theory and reality therapy in individual and group counseling in a Malaysian context. Journal of Public Administration, Finance \& Law, 15, 75-85.
8. U.S. Bureau of Labor Statistics. (2020, June). Local area unemployment statistics. https://www.bls.gov/web/laus/ laumstrk.htm

9. Center for Systems Science and Enginerring. (2021, September 2). COVID-19 dashboard. John Hopkins University. https:// gisanddata.maps.arcgis.com/apps/opsdashboard/index. html?fbclid=IwAR3prf7gRuznOnGiv_wZpjhVQYZAtQcVJY orx1Yfu3Tutt4nn2dUQaGbyo\#/bda7594740fd40299423467b4 8e9ecf6

10. Iqbal, M. (2020, June 23). Tinder revenue and usage statistics (2020). Retrieved July 06, 2020, from https://www. businessofapps.com/data/tinder-statistics/

11. Flynn, M. (2020, April 23). They lived in a factory for 28 days to make millions of pounds of raw PPT materials to help fight coronavirus. https://www.washingtonpost.com/ nation/2020/04/23/factory-masks-coronavirus-ppe/ 